\title{
Hydrogen Permeation and Diffusion through Pure Fe, Pure Ni and Fe-Ni Alloys
}

\author{
By Y. Yamanishi*, T. Tanabe** and S. Imoto**
}

\begin{abstract}
Hydrogen permeability and diffusivity of pure $\mathrm{Fe}$, pure $\mathrm{Ni}$ and $\mathrm{Fe}-\mathrm{Ni}$ alloys were determined using the gaseous permeation method in the temperature range from 473 to $1073 \mathrm{~K}$ under the hydrogen pressure ranging from 0.01 to $0.1 \mathrm{MPa}$. Values of both permeability and diffusivity for pure Ni and those of permeability for pure Fe agreed well with literature values. Arrhenius plot of diffusivity for pure $\mathrm{Fe}$ showed a good linear relationship to temperatures as low as $473 \mathrm{~K}$. Both permeability and diffusivity for $\mathrm{Fe}-\mathrm{Ni}$ alloys with less than 30 at $\% \mathrm{Ni}$ showed a sudden change due to the martensitic transformation $(b c c \rightleftarrows f c c)$ giving two distinct temperature dependences. The activation energies for both permeation and diffusion in $f c c$ phase were larger than those in $b c c$ phase. Variation of permeability and diffusivity with alloy composition was complicated, but, most of the values were found in the range between those for pure Fe and pure Ni. The rusults that the variation of permeability was similar to that of lattice parameter or that of magnetic moment of the $\mathrm{Fe}-\mathrm{Ni}$ alloys suggest the existance of some correlations between permeation phenomena and electric properties of the alloys.
\end{abstract}

(Received August 9, 1982) Keyzerds: hydrogen, permeability, diffusivity, iron, nickel, iron nickel alloys, gaseous per-
meation method, effects of crystal structure, martensitic transformation

\section{Introduction}

Hydrogen transport in iron and steel, which has been one of the key problems for hydrogen embrittlement, is now getting an increasing importance in recent development of nuclear fusion and/or hydrogen energy technology. Measurement of hydrogen diffusivity in pure iron has been carried out in plenty of works, but values of hydrogen diffusivity at temperatures below $600 \mathrm{~K}$ are widely scattered ${ }^{(1)(2)}$. Most of $b c c$ metals such as $\mathrm{Ti}, \mathrm{V}, \mathrm{Nb}, \mathrm{Mo}$ show some scattering of the diffusion data at high temperatures, and it has mainly been attributed to the effect of surface oxidation $^{(3)(4)}$. Fe is, however, easy to be reduced by hydrogen, so hydrogen diffusion in Fe may not be influenced by the surface oxide. At very low temperatures, on the other hand, hydrogen diffusion is enhanced by the tunneling effect in some metals ${ }^{(5)}$, but most of the diffusion data for $\mathrm{Fe}$ at temperatures below $600 \mathrm{~K}$ deviate

* Graduate Student, Osaka University, Suita, Osaka 565, Japan.

** Department of Nuclear Engineering, Faculty of Engineering, Osaka University, Yamadaoka, Suita, Osaka 565, Japan. downward from the values expected from extrapolation of high temperature data, and the cause of the deviation is considered to be due to trapping of hydrogen at defects ${ }^{(6)}$ or impurities $^{(7)}$. Oriani has clearly related the decrease in the apparent diffusivity in steel to the increase of density of trapping site in steel ${ }^{(8)}$. Choi showed that the increase of defects in cold worked iron leads to the decrease of diffusivity by one order of magnitude at $323 \mathrm{~K}^{(7)}$.

In contrast to $\mathrm{Fe}$, diffusion data for $\mathrm{Ni}$ show a good agreement with each other, and no appreciable effect of defects or impurities on the diffusivity has been observed ${ }^{(9)}$. In this respect, it may be much interesting to examine the hydrogen transport behavior of $\mathrm{Fe}-\mathrm{Ni}$ alloys not only for practical purpose but also for basic research, for example, of the trapping effect etc. Hydrogen diffusion in $\mathrm{Fe}-\mathrm{Ni}$ alloys has already been examined by several workers $^{(10)-(13)}$, but all the data except the Dus and Smialowski's result ${ }^{(11)}$ have been obtained only in a limited temperature range around room temperature using the electrochemical method. Neglecting a slight discrepancy, they generally give an agreed trend that both the diffusivity $(D)$ and the permeability $(\Phi)$ gradually decrease with increasing $\mathrm{Ni}$ 
content up to 20 at $\% \mathrm{Ni}$ and show a sharp drop by two or three orders of magnitude between 20 and 40 at $\% \mathrm{Ni}$. The variation of $\mathrm{D}$ and $\Phi$ in 40 to 100 at $\% \mathrm{Ni}$ is generally small. Dus and Smialowski ${ }^{(11)}$ (High temperature data) and Beck et al. ${ }^{(10)}$ analyzed their own data with a function of hypothetical mole fraction of $\alpha$ phase obtained from the equilibrium phase diagram. Such an assumption is, however, inadequate to be used for $\mathrm{Fe}-\mathrm{Ni}$ alloys except for those which have attained the two-phase equilibrium $^{(14)}$, because it is well known that the alloys with $\mathrm{Ni}$ content less than 30 at \% show rapid transformation (martensitic transformation) from the $f c c$ (austenite: $\gamma$ ) phase to the $b c c$ (martensite: $\alpha^{\prime}$ ) phase with decreasing temperature and from $\alpha^{\prime}$ to $\gamma$ with increasing temperature, and it takes a very long time for the alloys to reach the two-phase equilibrium $(\alpha+\gamma)$. In the present report are described the measurements of diffusivity and permeability of $\mathrm{Fe}-\mathrm{Ni}$ alloys for both $b c c$ and $f c c$ phases in the wide temperature region between 473 and $1073 \mathrm{~K}$ using the gaseous hydrogen permeation method, and the effect of variation in composition and crystal structure of the alloys on $\Phi$ and $D$ are discussed. Since the martensitic phase change is inevitable in the present temperature region, the effect of the phase change is also discussed.

\section{Experimental}

\section{Apparatus}

Figure 1 shows a schematic diagram of the apparatus for the measurement. The system is mainly made of stainless steel and divided by a disk-shaped specimen into two parts, i.e. the upstream side, where pure hydrogen is continuously supplied, and the downstream side, where permeating hydrogen is quantitatively analyzed. Prior to the measurement, the entire system was evacuated to better than $4 \times$ $10^{-6} \mathrm{~Pa}$ after bake-out with diffusion pumps with liq. $\mathrm{N}_{2}$ trap. Research grade hydrogen gas $(99.999 \%)$ was further purified with a uranium getter bed and supplied to the upstream side. Water vapor, the principal impurity in hydrogen gas, was gettered in the uranium bed to

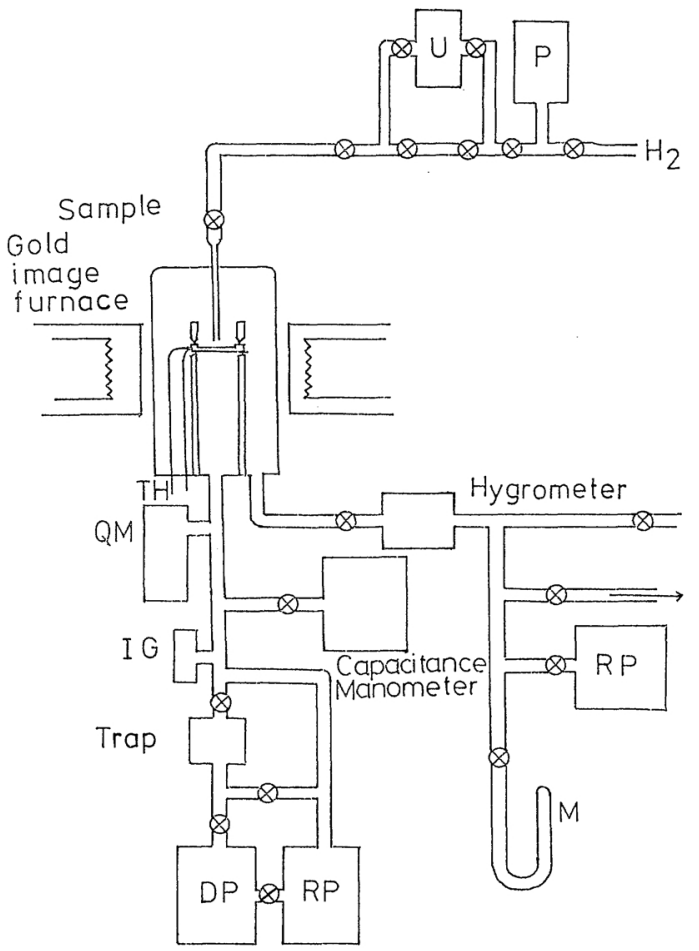

Fig. 1 Apparatus for measurements. (P: Pressure gauge, $U$ : Uranium getter bed for hydrogen purification, TH: Thermo couple, $\mathrm{M}$ : Hg-manometer, IG: Ionization vacuum gauge, DP: Diffusion pump, RP: Rotary pump).

several ppms at the outlet of the upstream side, where the concentration was monitored by a hygrometer. The hydrogen pressure at the upstream side measured by a $\mathrm{Hg}$-manometer was kept constant between 0.01 and $0.1 \mathrm{MPa}$ by controlling the amount of gas supply and the evacuation rate. From the view of oxygen potential consideration, such an amount of water vapor gives no problem to oxidation of $\mathrm{Fe}-\mathrm{Ni}$ alloys. The temperature of specimen in a gold image furnace (Shinku-Riko PHL-P-650) was kept constant within $\pm 2 \mathrm{~K}$ in the temperature region between 473 and $1073 \mathrm{~K}$. Permeating hydrogen at the downstream side was analyzed by a quadrupole mass spectrometer, and the total amount of permeating hydrogen was determined by a capacitance manometer (MKS Baratron 170-6C).

\section{Specimen}

Materials used in the present experiment 
Table 1 Chemical composition of Fe-Ni alloys (vacuum melted and forged).

(mass $\%$ )

\begin{tabular}{lccccccc}
\hline Alloy & \multicolumn{1}{c}{$\mathrm{C}$} & $\mathrm{Si}$ & $\mathrm{Mn}$ & $\mathrm{P}$ & $\mathrm{S}$ & $\mathrm{Ni}$ & $\mathrm{Fe}$ \\
\hline Fe3Ni & 0.002 & $\mathbf{0 . 0 0 1}$ & $\mathbf{0 . 0 0 5}$ & $\mathbf{0 . 0 0 5}$ & 0.006 & 3.09 & Balance \\
$\mathrm{Fe} 5 \mathrm{Ni}$ & $<0.005$ & $\mathbf{0 . 0 0 3}$ & $\mathbf{0 . 0 0 6}$ & $\mathbf{0 . 0 0 5}$ & 0.005 & 4.55 & Balance \\
$\mathrm{Fe} 6 \mathrm{Ni}$ & 0.002 & $\mathbf{0 . 0 0 1}$ & $<0.005$ & $<0.005$ & 0.005 & $\mathbf{6 . 0 2}$ & Balance \\
$\mathrm{Fe} 9 \mathrm{Ni}$ & 0.002 & 0.001 & $<\mathbf{0 . 0 0 5}$ & $<0.005$ & 0.005 & 9.07 & Balance \\
Fe12Ni & 0.001 & 0.001 & $<0.005$ & $<0.005$ & 0.006 & 11.82 & Balance \\
Fe20Ni & 0.001 & 0.005 & $<0.003$ & $<\mathbf{0 . 0 0 5}$ & 0.004 & 19.63 & Balance \\
Fe40Ni & 0.001 & 0.005 & $<0.003$ & $<0.005$ & 0.003 & 39.07 & Balance \\
Fe50Ni & 0.002 & 0.007 & $<0.006$ & $<0.005$ & 0.002 & 48.58 & Balance \\
\hline \hline
\end{tabular}

Fe: (HEK-GmbH) $5 \mathrm{~N}$.

$\mathrm{Ni}$ : (Johnson Matthey) $5 \mathrm{~N}$.

were pure $\mathrm{Fe}, \mathrm{Fe} 3 \mathrm{Ni}, \mathrm{Fe} 5 \mathrm{Ni}, \mathrm{Fe} 6 \mathrm{Ni}, \mathrm{Fe} 9 \mathrm{Ni}$, $\mathrm{Fe} 12 \mathrm{Ni}, \mathrm{Fe} 20 \mathrm{Ni}, \mathrm{Fe} 40 \mathrm{Ni}, \mathrm{Fe} 50 \mathrm{Ni}$ and pure Ni. In Table 1 are shown the chemical composition of the alloys. A circular disk specimen with effective surface area of $1.77 \times 10^{-4} \mathrm{~m}^{2}$ and thickness of ( 2 to 4$) \times 10^{-4} \mathrm{~m}$ was mechanically polished with $0.3 \mu \mathrm{m}$ alumina powder, linsed in acetone and annealed at about $1073 \mathrm{~K}$ for $36 \mathrm{ks}(10 \mathrm{~h})$ in vacuum better than $10^{-5} \mathrm{~Pa}$ after mounting on a sample holder made by 316 SS. Measurements of $\Phi$ and $D$ were started at $1073 \mathrm{~K}$ with various upstream side pressures of hydrogen, and similar measurements were carried out decreasing the temperature by $20 \mathrm{~K}$ for each step from 1073 to $473 \mathrm{~K}$. It takes about $3.6-18 \mathrm{ks}$ for the measurements at a given temperature. After standing the sample for several hours at room temperature similar runs were made with increasing temperature from 473 to $1073 \mathrm{~K}$.

\section{Method}

In the present study, the permeation rate and the diffusivity were determined separately. The former was done by the build up method and the latter by the evolution method.

\section{(1) Determination of permeation rate by build up method}

Hydrogen partial pressure at the downstream side begins to increase linearly with time shortly after the evacuation of the downstream side has stopped. Then the pressure rise $(\Delta P)$ in a time interval $(\Delta t)$ gives the hydrogen permeation rate $(Q)$ according to the equation,

$$
Q=\Delta P \times V / \Delta t,
$$

where $V$ is the volume of the downstream side. The permeability, $\Phi$, is defined as follows under the assumption that the permeation rate is proportional to the square root of pressure and inversely proportional to the thickness of the sample.

$$
\Phi=Q \times d /\left(\sqrt{P_{1}}-\sqrt{P_{2}}\right) \times A,
$$

where $P_{1}$ and $P_{2}$ are the hydrogen partial pressures $\left(P_{1} \gtrsim P_{2}\right)$ at the upstream side and the downstream side, respectively, and $d$ is the sample thickness and $A$ the effective surface area.

\section{(2) Determination of diffusivity by evolution method}

After establishment of the steady state permeation with continuous evacuation of the downstream side, hydrogen gas at the upstream side is pumped out $\left(P_{1} \rightarrow 0\right)$. Then the hydrogen partial pressure at the downstream side, $P(t)$, decreases according to the equation,

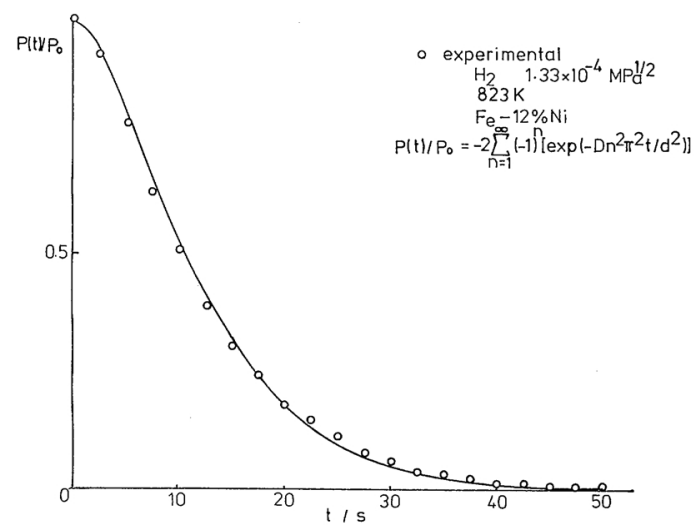

Fig. 2 Least square fitting of obtained permeation rate vs time to theoretical one. 


$$
P(t) / P(0)=-2 \sum_{n=1}^{\infty}(-1)^{n} \exp \left(-D n^{2} \pi^{2} t / d^{2}\right) .
$$

A sequence of obtained values $P(t)$ is very well fitted to eq. (3) as shown in Fig. 2, and the least squares fitting gives the values of $D$ with a high accuracy. The value of diffusivity determined by such an evolution method is generally more accurate than that obtained by the injection method ${ }^{(15)}$, because the former method is less influenced by the upstream side surface of the sample than the latter is.

\section{Experimental Result}

\section{Pure Fe and pure Ni}

Figures 3 and 4, respectively, show the Arrhenius plots of $\Phi$ and $D$ obtained in the present study for pure $\mathrm{Fe}$ and pure $\mathrm{Ni}$ and some literature data for a comparison. The present data, $\Phi$ and $D$, for $\mathrm{Ni}$ are seen to be in a fair agreement with the Robertson's best fits ${ }^{(16)}$. The values of $\Phi$ and $D$ for pure $F e$ also give a good linear relationship in the Arrhenius plot

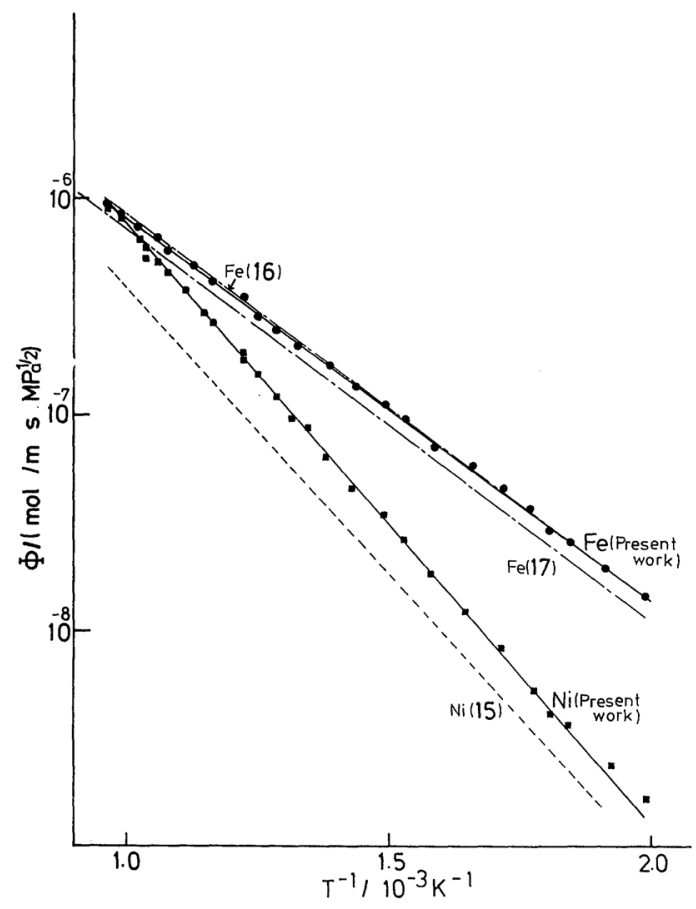

Fig. 3 Hydrogen permeabilities vs reciprocal temperature for pure $\mathrm{Fe}$ and $\mathrm{Ni}$.

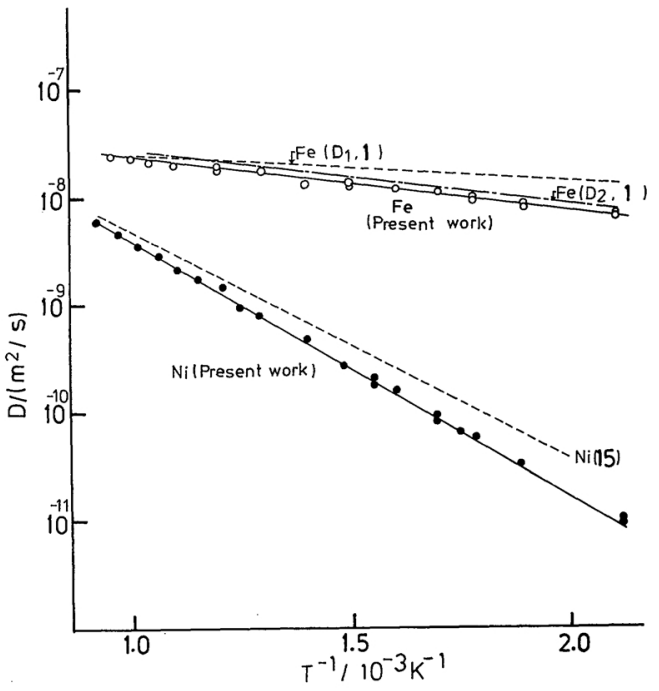

Fig. 4 Hydrogen diffusivities vs reciprocal temperature for pure $\mathrm{Fe}$ and $\mathrm{Ni}$. $\left(D_{1}\right.$ and $D_{2}$ were recommended values by Alefeld and Völkl ${ }^{(1)}$.)

in the wide temperature range between 473 and $1073 \mathrm{~K}$. Furthermore, $\Phi$ agrees well with recent data measured by the gaseous permeation method $^{(17)(18)}$. We have made a similar measurement also for rather impure Fe $(99.95 \mathrm{at} \%)$. Values of $D$ obtained, which are not shown here, were also in good agreement with those for pure $\mathrm{Fe}$, so impurities of about 0.05 at $\%$ in $\mathrm{Fe}$ do not seem to act as effective traps that cause the decrease of $D$ as far as the temperature is above $473 \mathrm{~K}$.

\section{2. $\mathrm{Fe}-\mathrm{Ni}$ alloys}

For all the Fe-Ni alloys, values of $\Phi$ and $D$ depend neither on the sample thickness nor on the inlet hydrogen pressure. Reproducibility of each data is very good and independent of sample history except in the case of Fe40Ni below $673 \mathrm{~K}$. Figures 5, 6 and 7, respectively, show the values of $\Phi, D$ and $S$ as a function of the alloy composition, $S=\Phi / D$ meaning the solubility of hydrogen in the alloys. The values of $\Phi$ and $D$ are seen to change with the Ni content in a complicated manner for the Fe-rich alloys in contrast to the Ni-rich region, for which the values show a rather mild change with increasing Ni content. The variation of $\Phi$ at higher temperatures is small, and all the values at $1073 \mathrm{~K}$ fall in a range within the factor of three. 


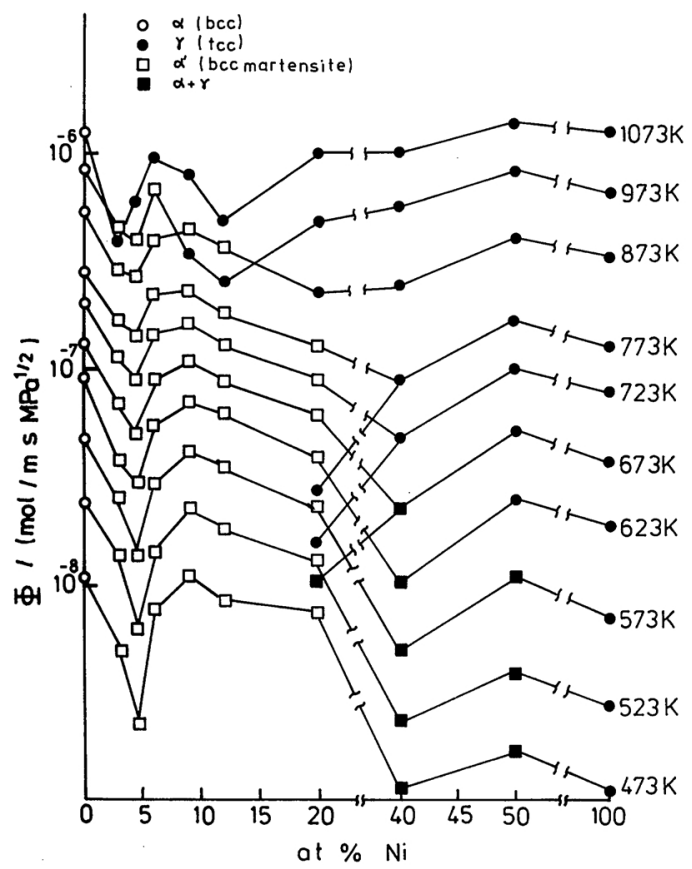

Fig. 5 Variation of hydrogen permeability according to mole fraction of the $\mathrm{Ni}$ in $\mathrm{Fe}-\mathrm{Ni}$ alloys.

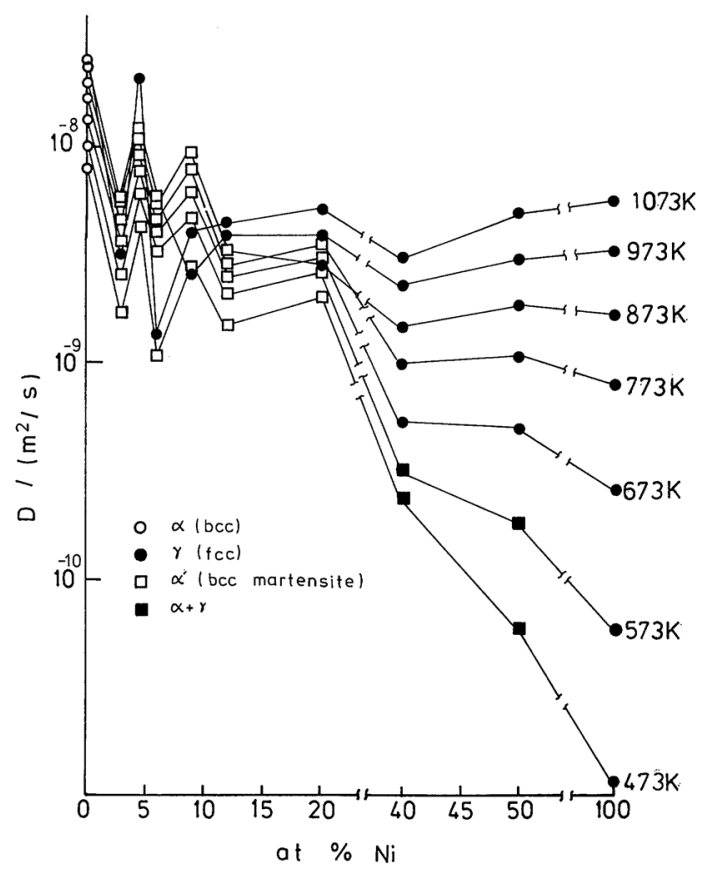

Fig. 6 Variation of hydrogen diffusivity according to mole fraction of the $\mathrm{Ni}$ in $\mathrm{Fe}-\mathrm{Ni}$ alloys.

In addition, most of values of $\Phi$ and $D$ are found in a region limited by values for pure $\mathrm{Fe}$

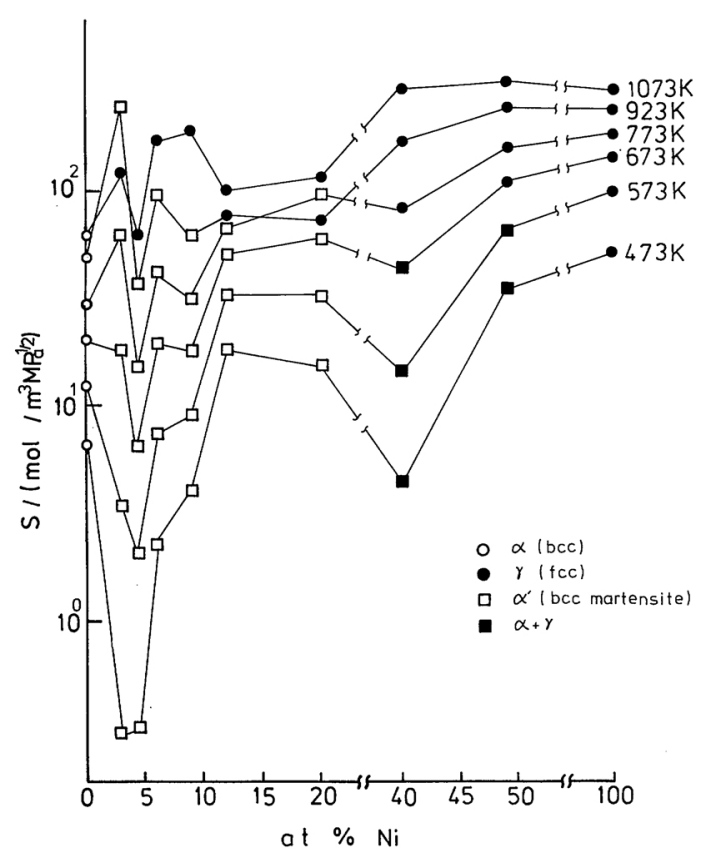

Fig. 7 Variation of hydrogen solubility according to mole fraction of $\mathrm{Ni}$ in $\mathrm{Fe}-\mathrm{Ni}$ alloys.

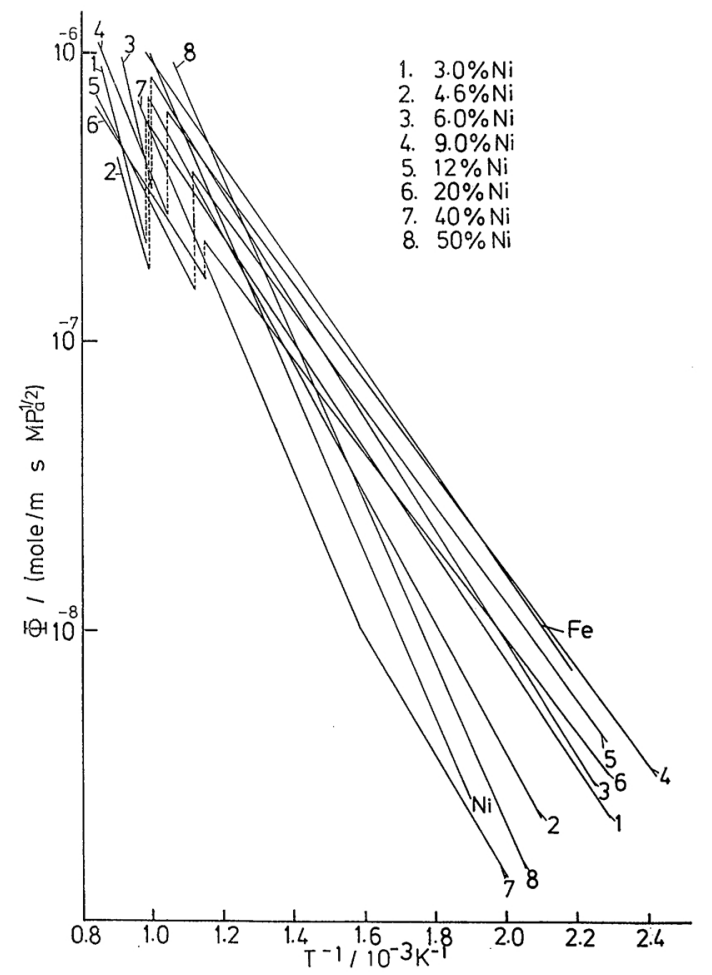

Fig. 8 Hydrogen permeabilities vs reciprocal temperature for $\mathrm{Fe}-\mathrm{Ni}$ alloys. 


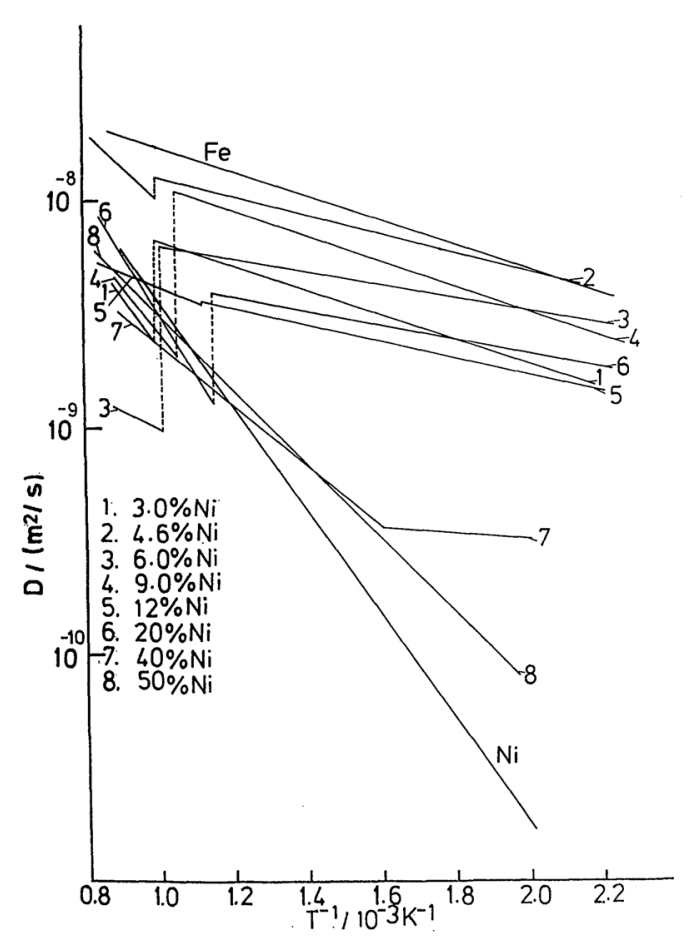

Fig. 9 Hydrogen diffusivities vs reciprocal temperature for $\mathrm{Fe}-\mathrm{Ni}$ alloys.

and those for pure Ni. Thus in the present temperature range $(473-1073 \mathrm{~K}), \mathrm{Ni}$ in Fe-rich alloys or $\mathrm{Fe}$ in $\mathrm{Ni}$-rich alloys does not appear to act as a trap site so effective as to decrease the values by an order of magnitude or more.

In Figs. 8, 9 and 10 are shown the Arrhenius plots of $\Phi, D$ and $S$, respectively, where it is clearly seen that values of $\Phi$ and $D$ for Fe-rich alloys are characterized by two different temperature dependences. In order to avoid the confusion, each data point is omitted in the figures. Errors in the measurement are seen in Tables 2 and 3, where are summarized the permeability and diffusivity, respectively.

Figure 11 shows the variation of permeability in Fe12Ni due to the martensitic transformation during heating and cooling. One can see a sudden drop of $\Phi$ due to the phase change from $b c c$ to $f c c$ during the sample heating and a step up of $\Phi$ during the cooling. In spite of rather fast heating or cooling rate $( \pm 0.17 \mathrm{~K} / \mathrm{s})$ compared with the time necessary for hydrogen diffusion (nearly equal to the square of sample thickness divided by the diffusivity), the tem-

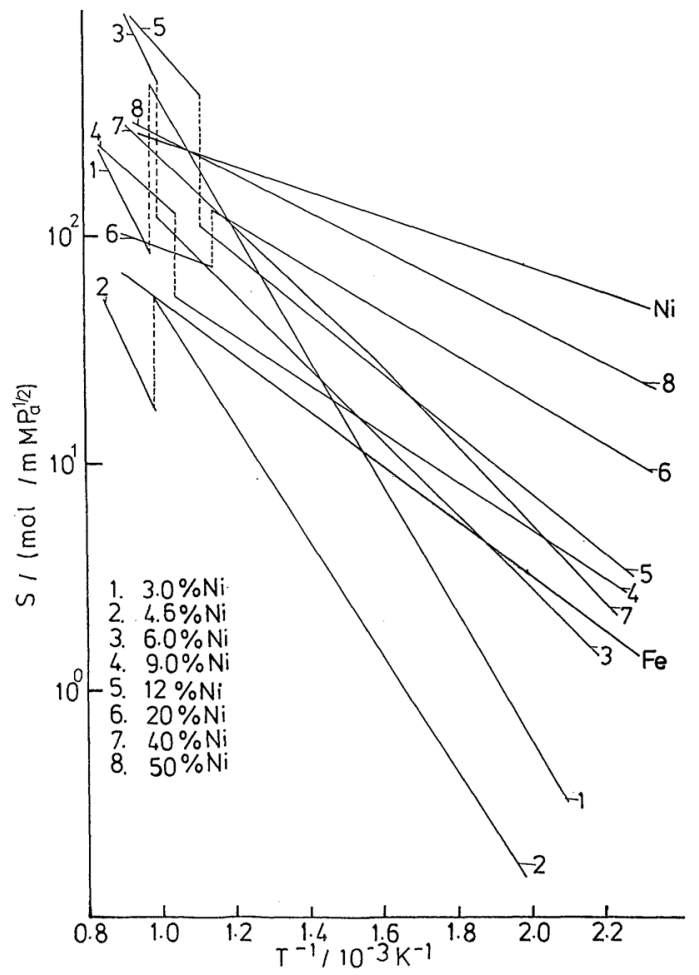

Fig. 10 Hydrogen solubilities vs reciprocal temperature for $\mathrm{Fe}-\mathrm{Ni}$ alloys.

peratures for the sudden change in $\Phi$ are in quite good agreement with those for martensitic transformation of the alloy ${ }^{(19)}$. That the Arrhenius relationship for $\Phi$ and $D$ is discontinuous at the transformation temperature is attributed to the different temperature dependence in $\Phi$ and $D$ between $b c c$ phase and $f c c$ phase. Discontinuities in $\Phi$ and $D$ due to the transformation from $f c c$ to $b c c$ during the cooling appeared at somewhat lower temperatures than those during heating because of hysteresis effect in the martensitic transformation. Increase of the Ni content lowers the transformation temperatures, so the values of $\Phi$ and $D$ for the $b c c$ phase are not obtained for the alloys with the $\mathrm{Ni}$ content more than 20 at $\% \mathrm{Ni}$ at about room temperature. The two-phase $(b c c+$ $f c c$ ) structure appears in high $\mathrm{Ni}$ alloys (40 at $\%$ $\mathrm{Ni}$ or above). Since it takes very long time to establish the two-phase equilibrium compared with martensitic transformation for the high $\mathrm{Ni}$ alloys, the data for such alloys (in the present work, $40 \mathrm{Ni}$ below $673 \mathrm{~K}$ ) are sensitive to the 
Table 2 Permeability in pure $\mathrm{Fe}$, pure $\mathrm{Ni}$ and $\mathrm{Fe}-\mathrm{Ni}$ alloys.

\begin{tabular}{|c|c|c|c|c|}
\hline $\begin{array}{l}\text { Alloys \& } \\
\text { metals }\end{array}$ & $\begin{array}{c}\Phi_{0} \\
10^{-4} \mathrm{~mol} / \mathrm{m} \mathrm{s} \mathrm{MPa}^{1 / 2}\end{array}$ & $\underset{\mathrm{kJ} / \mathrm{mol}}{E_{\Phi}}$ & $\begin{array}{c}\Phi_{0} \\
10^{-5} \mathrm{~mol} / \mathrm{m} \mathrm{s} \mathrm{MPa}^{1 / 2}\end{array}$ & $\underset{\mathrm{kJ} / \mathrm{mol}}{E_{\Phi}}$ \\
\hline & \multicolumn{2}{|c|}{ (fcc phase) } & \multicolumn{2}{|c|}{ (bcc phase) } \\
\hline $\mathrm{Fe}$ & & & $5.35 \pm 0.53$ & $33.6 \pm 1.5$ \\
\hline $\mathrm{Fe} 3 \mathrm{Ni}$ & $134 \pm 9$ & $92.6 \pm 6.2$ & $4.33 \pm 0.96$ & $53.7 \pm 1.4$ \\
\hline $\mathrm{Fe} 5 \mathrm{Ni}$ & $89.0 \pm 4.2$ & $97.9 \pm 4.8$ & $10.7 \pm 1.0$ & $42.6 \pm 1.2$ \\
\hline $\mathrm{Fe} 6 \mathrm{Ni}$ & $18.6 \pm 1.5$ & $67.6 \pm 3.2$ & $6.47 \pm 1.02$ & $36.8 \pm 1.8$ \\
\hline $\mathrm{Fe} 9 \mathrm{Ni}$ & $13.3 \pm 1.1$ & $67.7 \pm 3.1$ & $3.29 \pm 0.99$ & $31.6 \pm 1.5$ \\
\hline $\mathrm{Fe} 12 \mathrm{Ni}$ & $9.52 \pm 1.23$ & $48.1 \pm 2.7$ & $2.75 \pm 0.95$ & $31.9 \pm 1.9$ \\
\hline $\mathrm{Fe} 20 \mathrm{Ni}$ & $29.1 \pm 1.4$ & $71.0 \pm 1.5$ & $1.67 \pm 0.98$ & $31.4 \pm 2.1$ \\
\hline $\mathrm{Fe} 40 \mathrm{Ni}$ & $5.04 \pm 0.92$ & $56.3 \pm 1.4$ & & \\
\hline $\mathrm{Fe} 50 \mathrm{Ni}$ & $7.52 \pm 0.91$ & $52.5 \pm 1.2$ & & \\
\hline $\mathrm{Ni}$ & $7.08 \pm 0.82$ & $54.8 \pm 1.2$ & & \\
\hline
\end{tabular}

Table 3 Diffusivity in pure $\mathrm{Fe}$, pure $\mathrm{Ni}$ and $\mathrm{Fe}-\mathrm{Ni}$ alloys.

\begin{tabular}{lcccc}
\hline \hline $\begin{array}{c}\text { Alloys \& } \\
\text { metals }\end{array}$ & $\begin{array}{c}D_{0} \\
10^{-8} \mathrm{~m}^{2} / \mathrm{s}\end{array}$ & $\begin{array}{c}E_{\boldsymbol{D}} \\
\mathrm{kJ} / \mathrm{mol}\end{array}$ & $\begin{array}{c}D_{0} \\
10^{-9} \mathrm{~m}^{2} / \mathrm{s}\end{array}$ & $\begin{array}{c}E_{\boldsymbol{D}} \\
\mathrm{kJ} / \mathrm{mol}\end{array}$ \\
\hline & & & & $($ bcc phase $)$ \\
\hline $\mathrm{Fe}$ & & & $62.0 \pm 1.2$ & $10.5 \pm 1.3$ \\
$\mathrm{Fe} 3 \mathrm{Ni}$ & $11.4 \pm 1.4$ & $31.4 \pm 2.5$ & $19.3 \pm 3.0$ & $9.62 \pm 1.41$ \\
$\mathrm{Fe} 5 \mathrm{Ni}$ & $11.6 \pm 1.7$ & $47.7 \pm 5.8$ & $27.6 \pm 2.1$ & $6.95 \pm 1.63$ \\
$\mathrm{Fe} 6 \mathrm{Ni}$ & $0.619 \pm 0.052$ & $15.2 \pm 3.9$ & $12.0 \pm 1.5$ & $5.54 \pm 1.51$ \\
$\mathrm{Fe} 9 \mathrm{Ni}$ & $31.5 \pm 2.3$ & $39.8 \pm 2.3$ & $42.7 \pm 1.8$ & $10.8 \pm 1.9$ \\
$\mathrm{Fe} 12 \mathrm{Ni}$ & $1.08 \pm 0.95$ & $12.1 \pm 1.7$ & $8.34 \pm 1.6$ & $6.62 \pm 1.51$ \\
$\mathrm{Fe} 20 \mathrm{Ni}$ & $155 \pm 1$ & $51.7 \pm 1.8$ & $8.78 \pm 1.7$ & $6.01 \pm 1.21$ \\
$\mathrm{Fe} 40 \mathrm{Ni}$ & $4.92 \pm 0.85$ & $25.5 \pm 1.3$ & & \\
$\mathrm{Fe} 50 \mathrm{Ni}$ & $37.6 \pm 1.0$ & $36.4 \pm 1.2$ & & \\
$\mathrm{Ni}$ & $74.3 \pm 2.3$ & $44.1 \pm 1.2$ & & \\
\hline \hline
\end{tabular}

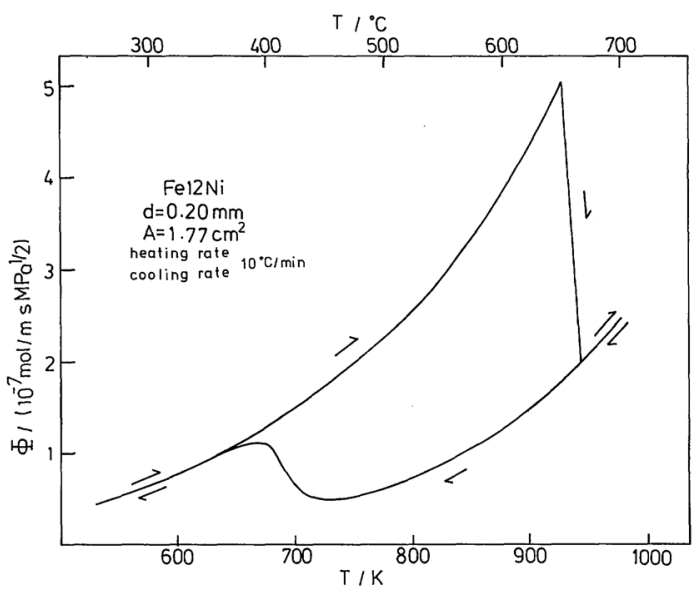

Fig. 11 Change in hydrogen permeability during heating up (upper curve) and cooling down (lower curve).

thermal history of the alloy and may have some error.

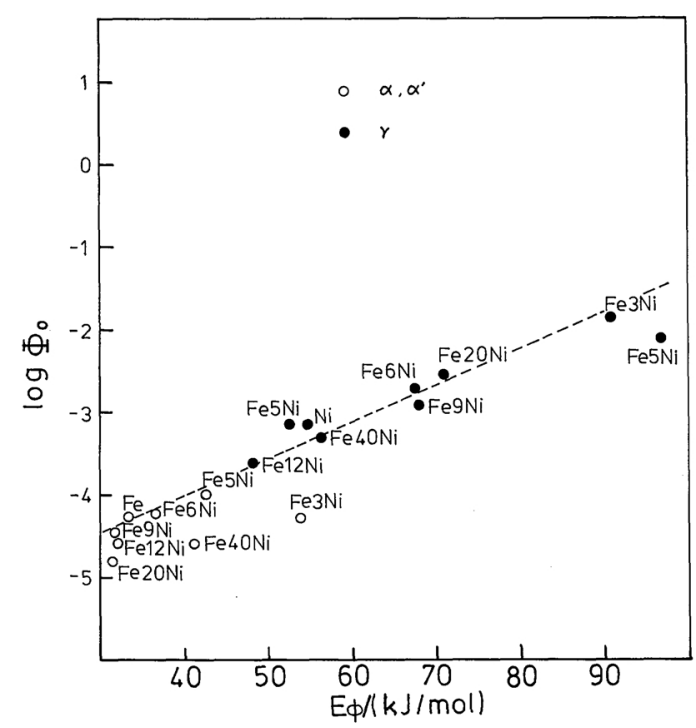

Fig. 12 Compensation effect observed in semi-log plot of pre-exponential factor vs activation energy for hydrogen permeation. 
From Tables 2 and 3 one can see that in the Fe-rich alloys both activation energies $\left(E_{\Phi}\right.$ and $\left.E_{D}\right)$ and pre-exponential factors $\left(\Phi_{0}\right.$ and $\left.D_{0}\right)$ are smaller in the $b c c$ phase than in the $f c c$ phase.

The changes in activation energy and preexponential factor with the alloy composition are so complicated that it seems almost impossible to find a simple relationship among them. In reality, however, a semi-log plot for the pre-exponential factor vs the activation energy gives a good linear relationship as shown in Fig. 12. Such a relation is quite similar to the so-called compensation effect, i.e. linear relationship of logarithm of pre-exponential factor and activation energy in reaction rate constant, often appearing in the study of catalytic reaction rate $^{(20)}$, for which the meaning has not yet been made clear.

\section{Discussion}

Beck et al. ${ }^{(10)}$ have determined $\Phi$ and $D$ in the temperature range between 273 and $373 \mathrm{~K}$ with the electrochemical method. They observed a maximum in $\Phi$ at $5 \mathrm{at} \% \mathrm{Ni}$ and suggested that extrapolation of the data to higher temperatures should give extraordinarily large values. Indeed, their data are nearly comformable with the present data at lower temperatures in that $\Phi$ takes a local minimum at about 4 at $\% \mathrm{Ni}$ and a maximum at about 9 at $\% \mathrm{Ni}$. However, these local changes in $\Phi$ become inconspicuous at higher temperatures, and the present result obtained at high temperatures does not show such large values as suggested by Beck et al. The determination of the activation energy by Beck et al. in a narrow temperature range may have mislead them to extraordinarily high values when extrapolated to high temperatures. On the other hand, the values of $D$ extrapolated to lower temperatures in the present work agree with those given by Beck et al. and Dresler et al. except slight discrepancies, as shown in Fig. 13. Dresler and Frohberg showed that an appreciable drop in $D$ by a factor of three occurred with increasing Ni content from 0.04 to 0.15 at \% and that $D$ slightly decreased between 0.15 and 5 at $\% \mathrm{Ni}$ and furthermore decreased by about three orders between 5 and 30 at $\% \mathrm{Ni}$ at $298 \mathrm{~K}$, while

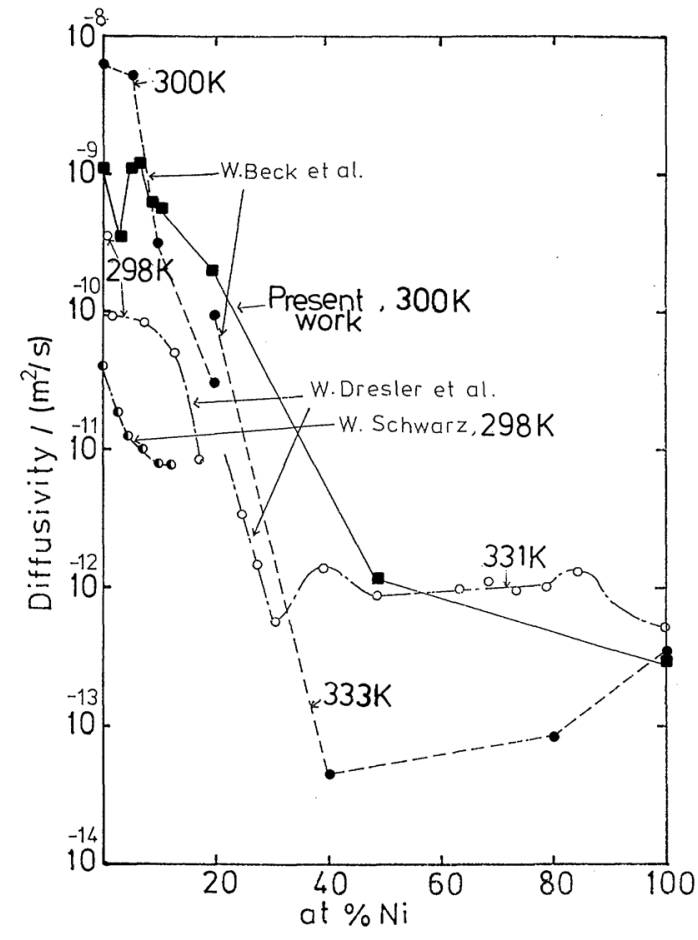

Fig. 13 Comparison of the present diffusivity (extrapolated to lower temperatures) for $\mathrm{Fe}-\mathrm{Ni}$ alloys with those of previous works.

Beck et al. missed the first drop and values of $D$ in the alloy with 5 at $\% \mathrm{Ni}$ were only slightly smaller than that of pure Fe. (see Fig. 13) The present values of $D$ for the alloy of 3 at $\% \mathrm{Ni}$ extrapolated to room temperature is, similarly to Dresler and Frohberg, smaller than the value of pure $\mathrm{Fe}$ by a factor of about three, however, the increment of Ni content results in a recovery of the values near to those of pure $\mathrm{Fe}$ in agreement with Beck et al. ${ }^{(10)}$. The further increase in the $\mathrm{Ni}$ content from 20 to 40 at $\% \mathrm{Ni}$ gives a sharp drop by about three orders of magnitude due to the phase change from $b c c$ to $f c c$, and the change in $D$ in the $f c c$ region remains to be small.

Beck et $a .^{(10)}$ and Dresler et $a .^{(12)}$ have tried the explanation for the complex relation between $D$ and the Ni content by assuming a contribution to $D$ proportional to mole fraction of hypothetical $b c c$ phase estimated from the phase diagram. This explanation, however, can not be applied to our case, because the present alloys are not able to avoid the martensitic 
transformation due to the wide temperature range of measurements such as seen in Fig. 11. The alloys $(5-20$ at $\% \mathrm{Ni})$ appear as homogeneous $\gamma$ above the martensitic transformation temperature and as martensite $\left(\alpha^{\prime}\right)$ below the temperature, thus showing always a single phase. Furthermore, Arrhenius plots of both $D$ and $\Phi$ for each alloy do not depend on the heating and cooling rate in the range of $0.017-$ $0.33 \mathrm{~K} / \mathrm{s}$ whether the alloy is in the state of $\gamma$ phase or $\alpha^{\prime}$ martensite. If we consider that $\alpha^{\prime}$ martensite in the $\mathrm{Fe}-\mathrm{Ni}$ alloys is crystallographically the same as $\alpha b c c$ phase except that the former has much more defects than the latter, we are led to the supposition that $\Phi$ and $D$ are not so much influenced by the defects in the temperature region. That some of intrinsic properties should show the similar trend to $\Phi$ and $D$ may reinforce this supposition. Zwell et al. ${ }^{(21)}$ have shown that the lattice parameter at $296 \mathrm{~K}$ for the $b c c$ phase of $\mathrm{Fe}-\mathrm{Ni}$ alloys increases with the content of $\mathrm{Ni}$ and reaches a maximum followed by a sharp decrease at about 13 at $\%$ Ni. Shiga ${ }^{(22)}$ has measured the change in the lattice parameter in the Ni-rich alloys (30-100 at $\% \mathrm{Ni}, f c c$ phase). With increasing $\mathrm{Fe}$ content from pure $\mathrm{Ni}$, the lattice parameter increased untill about 50 at $\% \mathrm{Ni}$ showing a slight deviation from the Vegard's law towards lower values. These variation of lattice parameter both in the $b c c$ phase and in the $f c c$ phase in $\mathrm{Fe}-\mathrm{Ni}$ alloys are quite similar to those of $\Phi$. The change in the magnetic moment of $\mathrm{Fe}-\mathrm{Ni}$ alloys with the alloy composition as given by Dresler et $a .^{(12)}$ is also similar to the variation of $\Phi$. The variation of $\Phi$ and $D$ with composition, thus, appears to be related with the intrinsic physical and electrical properties of the $f c c$ and the $b c c$ phases, and the defect in martensite seems to have minor effect on $\Phi$ and $D$ in the present temperature region. The hydrogen trapping effects due to defects in the alloys, however, can not completely be neglected especially in $\alpha^{\prime}$ martensite because of their high defect density as well as in pure $\mathrm{Fe}^{(6)}$, into which defects are much easily introduced, and such defect trapping in the alloys may be a part of the reason for the discrepancies among the various data (see Fig. 13) as discussed above.

\section{Conclusion}

In the present work, we have measured the permeability and diffusivity of pure $\mathrm{Fe}$, pure $\mathrm{Ni}$ and $\mathrm{Fe}-\mathrm{Ni}$ alloys using the gaseous permeation method in the wide temperature range between 473 and $1073 \mathrm{~K}$ with inlet hydrogen pressure of 0.01-0.1 MPa.

(1) The values of both $\Phi$ and $D$ for pure $\mathrm{Ni}$ is in quite good agreement with Robertson's best fits, and those of $\Phi$ for pure Fe also agree well with the literature values in the temperature range between 473 and $1073 \mathrm{~K}$. The Arrhenius relation for $D$ vs $1 / T$ gives a good linearity without any deviation, and the values coincide very well with the values $D_{2}$ recommended by Alefeld et al.

(2) It is noticable that both $\Phi$ and $D$ for $\mathrm{Fe}-\mathrm{Ni}$ alloys with the $\mathrm{Ni}$ content less than 30 at $\%$ give a sudden change due to the martensitic transformation from $f c c$ to $b c c$ (decreasing temperature) or vice versa. So two distinct Arrhenius relations exist in an alloy, i.e. one with a small activation energy for the $b c c$ phase and the other with a larger activation energy for the $f c c$ phase.

(3) Although the values of both $\Phi$ and $D$ for $\mathrm{Fe}-\mathrm{Ni}$ alloys change in a complicated manner with the alloy composition, most of them are found in the range between those for pure $\mathrm{Fe}$ and pure Ni. The extrapolated values of $D$ to room temperature are generally in agreement with the literature values. It is, however, difficult to give a simple relation between the values of pre-exponential factor as well as the activation energy for $\Phi$ and $D$ and the alloy composition.

(4) It is impossible to find a simple relationship among activation energy and pre-exponential factor for $\Phi$ and $D$, but a semi-log plot for the pre-exponential factor vs the activation energy gives a good linear relationship which is similar to the so-called compensation effect.

(5) The variation of $\Phi$ is similar to that of the lattice parameter and that of the magnetic moment of the Fe-Ni alloys. This fact suggests the presence of some correlation of diffusion and permeation phenomena with more intrinsic properties of the alloy. 


\section{Acknowledgements}

We make a grateful acknowledgement for Dr. Nasu (Osaka Univ.) who offered pure Fe, and for Dr. Mori (Kobe Steel Making Co. Ltd.) who offered the Fe-Ni alloys.

\section{REFERENCES}

(1) G. Alefeld and J. Völkl: Diffusion in Solids, ed. by A. S. Nowick et al., Academic Press, N.Y., (1975), p. 250.

(2) A. McNabb and P. K. Foster: Trans. Met. Soc. AIME, 227 (1963), 618.

(3) G. R. Caskey, Jr.: J. Nucl. Mater., 55 (1975), 279.

(4) T. S. Elleman and K. Verghese: J. Nucl. Mater., 53 (1974), 299.

(5) M. Tada and F. E. Fujita: Proc. 2nd JIM Int. Symp. on Hydrogen in Metals, Supplement to Trans. JIM, Vol. 21 (1979), p. 169.

(6) J. Y. Choi: Met. Trans., 1 (1970), 911.

(7) R. Gibala: Trans. Met. Soc. AIME, 239 (1967), 1574.

(8) R. A. Oriani: Acta Met., 18 (1970), 147.

(9) G. Alefeld and J. Völkl: Diffusion in Solids, ed. by
A. S. Nowick et al., Academic Press, N.Y., (1975), p. 248.

(10) W. Beck, J. O'M. Bockris, M. A. Genshaw and P. K. Subramanyan: Met. Trans., 2 (1971), 881.

(11) R. Dus and M. Smialowski: Acta Met., 15 (1969), 1611.

(12) W. Dresler and M. G. Frohberg: Iron Steel Inst., 211 (1973), 298.

(13) W. Schwarz and H. Zitter: Arch. Eisenhüttenw, 36 (1965), 343.

(14) R. W. Floyd: Institute of Metals Annotated Equilibrium Diagrams Series, No. 11, The Institute of Metals, London, (1955).

(15) M. R. Louthan, Jr. and R. G. Derrick: Corros. Sci., 15 (1975), 117.

(16) W. M. Robertson: Z. Metallk., 64 (1973), 436.

(17) R. F. Miller, J. B. Hudson and G. S. Ansell: Met. Trans. A, 6 (1975), 117.

(18) K. Masui, H. Yoshida and R. Watanabe: Trans. Iron Steel Inst. Japan, 19 (1979), 547.

(19) L. Kaufman and M. Cohen: Trans. AIME, 206 (1956), 1393.

(2) G. C. Bond: Catalysis by Metals, Academic Press, N.Y., (1962), p. 139.

(21) L. Zwell, D. E. Carnahan and G. R. Speich: Met. Trans., 1 (1970), 1007.

(22) M. Shiga: Solid State Commun., 10 (1972), 1233. 